\title{
Em Busca do Modelo Brasileiro
}

ALBERTO ANDRE

Diretor da Faculdade dos Meios de Comunicação da

Pontifícia Universidade Católica do Rio

Grande do Sui

Em abril de mil novecentos e setenta e três deve acontecer, em Porto Alegre, algo diferente na vida politico-administrativa do Rio Grande. O Conselho Metropolitano de Municípios e O Grupo Executivo da Região Metropolitana estarão apresentando, conCluído e testado, o Plano Diretor da Região Metropolitana de 14 comunas. Poderá ser o segundo do Brasil, eis que até agora apenas a Grande São Paulo elaborou o seu. O do Grande Rio está nos estudos preliminares, sob os auspícios do Ministério do Interior. Das outras seis áreas polarizadas parece que vai progredindo a de Belo Horizonte, mas a de Porto Alegre exibirá aspecto considerado único até aqui, o da participação efetiva dos municípios escolhidos e de alguns outros que desejam, de qualquer maneira, ingressar no sistema.

Brasil acordou timidamente para a problemática das concentrações urbanas e sua expansão nestes dez anos. Antes de definir e legislar, apontou logo pelo IBGE nove aglomerados com características de regionalização, sem excluir outras. O constituinte de 1967 resolveu incluir dispositivo na lei maior, representando a iniciativa $\circ$ primeiro esforço válido que se fez na República para diversificar a organização municipal.

No mundo, a crônica das regiōes metropolitanas pode estar concluindo um século, desde que o fenômeno da urbanização, fruto da revolução industrial, empolgou ou agravou veteranas cidades. O processo de crescimento urbano ultrapassou os limites do município, do burgo ou do condado, exigindo o rompimento da estrutura tradicional entre as unidades político-administrativas e suas instituiçőes. Londres pode ter sido a primeira área metropolitana européia; Nova lorque, a primeira americana. Buenos Aires, talvez a primeira sul-americana, S. Paulo a de maior crescimento. Estamos diante de processo em que os fatos e as realizaçōes avançaram mais do que a ciência $\mathrm{e}$ as definições. 
Objetivamos, em três trabalhos, expor a situação das áreas metropolitanas, principiando com aspectos de fora, seguindo-se a paisagem brasileira e, no final, a rio-grandense. Trata-se, evidentemente, de composição jornalística visando apenas a divulgação sem qualquer outro intulto.

\section{CONCEITO \& VOCABULÁRIO}

A gente poderá estar agredindo um técnico, urbanista, engenheiro ou arquiteto, se the perguntar à queimaroupa o que é "área metropolitana", "região metropolitana", "conurbação" e outras expressões utilizadas nesta operação já secular, mas ainda buscando seu estuário. Os três técnicos que integram o Grupo Executivo da Região Metropolitana de Porto Alegre, Srs. Danilo Landó, Umberto Pergher e Militão de Morais Ricardo, esclarecem ao jornalista: "A diferença é questão de origem e filosofia. Metrópole é a cidade-base. Área metropolitana, a que oferece os fenômenos dos aglomerados e sua expansão. Região, de âmbito maior, sobre a qual recai o planejamento."

Acham eles, no entanto, que o termo "Região Metropolitana" vai ganhando textos, colunas e linguagem no Brasil. A explicação é válida ante a conveniência da conscientização popular $\theta$ de liderança indispensável à execução do Plano Diretor, o que aqui sucederá a partir de 1973.

Em relatório e anteprojeto de lei enviados recentemente ao Ministério da Justiça e do Interior, o Instituto de Planejamento Econômico e Social (IPEA), do Ministério do Planejamento, ficou com as expressões "Área", para designar a polarização, e
"Região", contendo as tendências atuais do crescimento e o planejamento.

Como a linguagem cientifica se enriquece em todas as especialidades, é natural que isso igualmente ocorra com o urbanismo. O Prof. Hans Blumenfeld, da Universidade de Toronto, no artigo A Metrópole Moderna (Cidades, a Urbanização da Humanidade, edição Zahar, 1970), vem em nosso socorro, comentando: "Lewis Munford, que é o maior filósofo das cidades, é a favor do termo "conurbação", inventado por Patrick Geddes, o escocês tido como pioneiro do planejamento urbano - é a junção de cidades em expansão. Megalópole, empregado pelo geógrafo francês Jean Gottmann, é aplicado à região urbanizada contendo áreas metropolitanas. Metrópole batiza o grande centro urbano."

Os responsáveis pelo projeto gaúcho puseram de lado as divergências de conceito de linguagem e conteúdo e estão planejando uma "Região Metropolitana", a da Grande Porto Alegre. Apenas o Eng: Jorge Englert, Secretário de Desenvolvimento e Serviços Públicos (antiga SOP), esclarece ao repórter: "Há obras em andamento ou em estudos no território da RM. Elas não podem parar, pelo que serão analisadas e adaptadas quando possivel. Não podemos pretender que a Região pare para que seja planejada. Dal a vantagem do sistema de planejamento e da obtenção de alternativas para solucionar os problemas identificados".

FÓRMULAS \& DIREÇAO

Respondendo a questionário da Câmara dos Deputados; quando da apreciaçăo de projeto de lei sobre a especialidade, o Serviço Federal de $\mathrm{Ha}^{-}$ 
bitação e Urbanismo informou que, embora possa haver semelhanças dos nossos estudos com as verdades metropolitanas dos Estados Unidos, tudo indica "estarmos no Brasil em vésperas de um modelo próprio".

Esta posição atende à explicação do Ministro do Interior, Costa Cavalcanti, ao tranqüilizar, semanas atrás, a administração do Estado da Guanabara Segundo ele, o planejamento integrado das regiöes metropolitanas, partindo de conceitos genéricos, buscará aos poucos as realidades regionais brasileiras. Poderia alguém estranhar a presença, aqui, dos técnicos alemães, cuja áreas metropolitanas são inferiores em território e população às nossas em andamento. $O$ chefe de equipe, prof. Hans-Juergen Karpe, presente à entrevista com o Grupo Executivo, comenta:

- As áreas metropolitanas devem ser planejadas em cada caso. Mas as causas são comuns e as providências também, embora umas mais amplas do que as outras. Em todas as regiões metropolitanas destaca-se, por exemplo, um princípio que todos estão aplicando, o da descentralização e do restabelecimento do equilibrio. Isto quer significar medidas de profundidade, para progredir outras cidades e áreas, de maneira a restabelecer o equilibrio comprometido pelo aglomerado em expansão.

0 prof. Hans Blumenfeld, escrevendo que ele e o prof. alemão Gerhardt Isenberg observaram como cidades se transformaram em metrópoles na primeira metade deste século, forneceu estas medidas para a área metropolitana: concentração de pelo menos 500.000 almas, vivendo em área na qual o tempo de viagem dos subúrbios mais afastados até o centro não é maior do que 40 minutos. Poderíamos aduzir que este seria o modelo europeu. O governo da República Federal da Alemanha estabeleceu como um dos fatores, para a construção de subway nas cidades, precisamente a população de 500.000 habitantes. Quando Londres recebeu o seu metropolitano, por volta de 1865 , tinha pouco mais de um milhão de almas, o mesmo acontecendo a Paris, em 1900.

Nos Estados Unidos havia, no final da década de 60, aproximadamente 170 áreas metropolitanas, tendo o condado como unidade regional. Quem o enuncia é Austin F. MacDonald (Gobierno y Administración Municipal, edição Fundo de Cultura, 1959). O Departamento de Recenseamento havia definido a "área" como núcleo urbano em expansão com pelo menos 50.000 habitantes. A explosão demográfica destes lustros modificou este conceito, elevando-se para trezentos mil e mais. 0 certo é que o "urbanismo no séculc $X X$ ganhou a feição de cidades gigantescas, que influenciam toda a sociedade, tanto urbana, como rural (A Cidade e o Homem, de Gist e Halbert, edição Fundo de Cultura, 1961)". O modelo norte-americano poderia ter conceituação mais clara se the juntarmos a filosofia do "federalismo criador", com que o ex-presidente Johnson narrou em mensagem ao Congresso dos EUA, em 1965, os Problemas e futuro da cidade central e seus subúrbios. É a obtenção de regime intermediário, entre o Município e o Estado, capaz de fornecer as exatas dimensões institucionais da nova unidade em formação, que é a área metropolitana. 


\section{CIDADES \& CAMPOS}

Recorri aos quadros demográficos do Population Reference Bureau, que a ONU mantém na Colômbia, mas não consegui $\circ$ que deseja anotar: qual a imagem presente da população urbana? Somos, segundo o quadro mais recente, 3.632.000.000 de almas e poderemos ser 7,5 ou 6,1 bilhões no ano 2.000 , conforme maior ou menor limitação de nascimentos.

Apesar da migração das cidades para os subúrbios, na Europa persiste o gravame da intensificação das zonas urbanas. O campo tem sido salvo pelas leis e pela mecanização. Na América Latina mantém-se a advertência de Galo Plaza, como secretário da OEA, em 1968: "As populações urbanas estão crescendo a uma taxa anual de 5 a $7 \%$, o dobro do aumento da população do Hemisfério." A projeção no nosso País para 1980 é de 134 milhões, com talvez $80 \%$ de população urbana, um quarto vivendo nas 9 áreas metropolitanas apontadas e em cada cinco pessoas uma vivendo na faixa do eixo São Paulo-Rio.

As causas das áreas metropolitanas são mais ou menos as mesmas, incluindo, no quadro brasileiro, um fator agudo de maior gravidade. É o êxodo do campo para a cidade, em busca de emprego e melhor vida, sem que a cidade tenha recursos com que atender. O relatório do IPEA aponta estas características das áreas: 1 - grande concentração populacional; 2 complexidade e multiplicidade de funções; 3 - extensão da área urbanizada sobre o território de mais de uma unidade administrativa; 4 - integração econômica e social do conjunto.
Ainda sobra para a região brasileira - campo, mas a metrópole européla, segundo Hans Blumenfeld, ela "não é nem cidade, nem campo, e sim complexo de distritos urbanos e áreas verdes". Acham os entendidos que no planejamento das regiőes brasileiras o modelo terá mesmo de ser nacional, aproveitadas as técnicas e a experiência européias e americanas para a elaboração dos planos diretores.

\section{POLITICA \& ADMINISTRAÇAOO}

Quanto à população e aos problemas, - programa é mais ou menos semeIhante. As grandes áreas enfrentam 0 problema político, principalmente nos paises federativos. Nos EUA, a unidade menor, ao expandir-se na direção das outras, encontra o somatório de autonomia e atribuições do Municíplo e do Estado, o que exige a participaçăo federal. Fol o que levou Johnson a empregar, em sua mensagem, o termo "federalismo criador", já apontado. As federações, para sobreviverem, terăo de aceitar as adaptaçōes determinadas pelo agravamento dos problemas da época $\theta$ o fortalecimento do poder central.

Nos Estados unitários, a equação revela-se mais simples. A Grande Londres, agora com 10.000.000, está dividida em 32 municípios e a City, coordenado o processo administrativo global pelo Ministério do Interior. Resenha há pouco publicada mostra a que volume chegamos, em matéria de $\mathrm{re}^{-}$ gião metropolitana, e a soma e complexidade de operaçőes que significa sua administração. Moscou e Parls $\theta^{-}$ tão se aproximando dos 8.000 .000 de habitantes; Buenos Aires fica nos 7.000.000; Nova lorque está alcançan- 
do os 11.500.000; e Tóqulo; que é a maior de todas, se exibe com ....... 12.865.000. Os dramas de todos são iguais: poluição, habitação, transportes, trânsito, abastecimento, emprego, isolamento na massa, diferenciando-se apenas o padrão de vida.

Em todas estas metrópoles, um dos aspectos do tratamento parece demonstrar a síntese entre os velhos e novos mundos, que é a política de descentralização e procura do reequilíbrio. O Poder Central chama a si a legislação, institui os esquemas administrativos, promove ajuda econômica e financeira, e determina a execução em niveis regionais e até locais. Assim é na Alemanha ou nos Estados Unidos, em que predomina a sociedade democrática. Do outro lado, os elementos são escassos, mesmo para rudimentar apreciação jornalística.
O documento do IPEA, as afirmações do Ministro Costa Cavalcanti e o teor dos projetos, estão nos apontando um rumo. Será preservada a autonomia municipal. A organização que vai atuar, autarquia, empresa pública, ou de outra forma jurídica a ser deferida, como a fundação ou a sociedade de economia mista, será simplesmente administrativa, com poderes suficientes para planejar e executar aquelas medidas que, extravasando o limite municipal ou estadual, sejam do interesse comum das unidades de Região Metropolitana.

Aqui a última indagação: a região fará o homem feliz e eliminará suas angústias? Eis uma seara rica para nossos sociólogos e demais estudiosos, alguns agora envolvidos com a pesquisa do lazer.

\section{A POPULAÇÃ DE ALGUMAS METRÓPOLES}
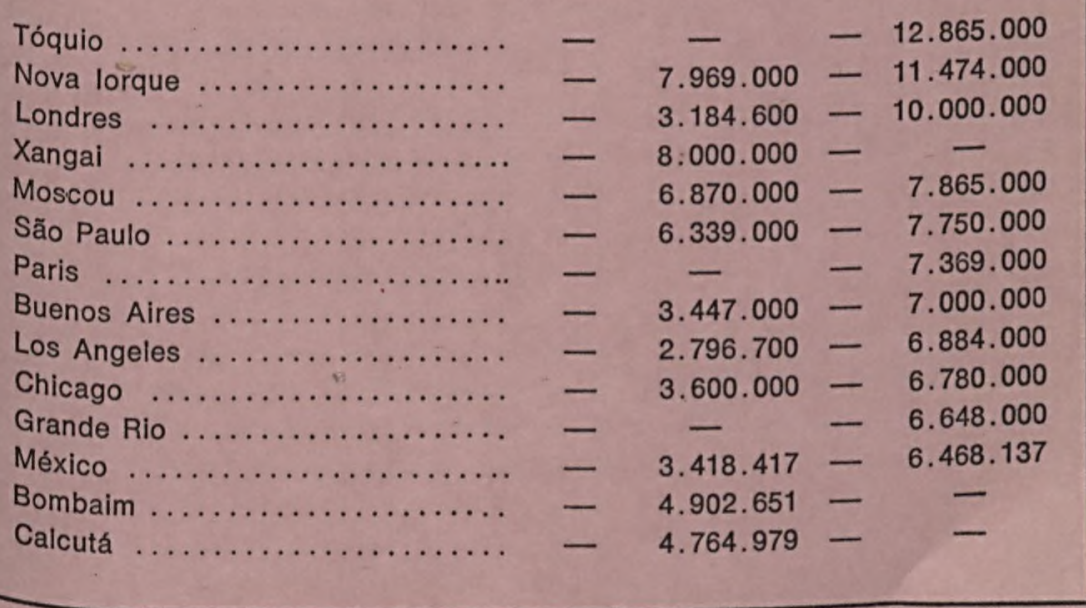

(Dados publicados em 1970) 